\title{
Study of Changes in Smoking Behavior among Moscow Population after Implementation of a Complex Antismoking Measures
}

\author{
VF Levshin* and NI Slepchenko \\ N.N Blokhin National medical research center of oncology, Russia \\ *Corresponding author: Levshin VF, N.N Blokhin National medical research center of oncology, 115478 Moscow, Russia
}

\section{ARTICLE INFO}

Received: 彗 July 09, 2019

Published: 㓞 July 16, 2019

Citation: VF Levshin, NI Slepchenko. Study of Changes in Smoking Behavior among Moscow Population after Implementation of a Complex Antismoking Measures. Biomed J Sci \& Tech Res 19(4)-2019. BJSTR. MS.ID.003343.

Keywords: Smoking Prevalence; Smoking Intensity; Secondhand Smoking; Changes of Smoking Behavior

\section{ABSTRACT}

Objective: To study changes in the prevalence and intensity of tobacco smoking among population in relation to gender and age, to evaluate effect of the tobacco control measures which were provided by the anti-smoking law in 2013.

Material and Methods: The population-based survey of the sample of Moscow adult population was conducted in 2017 - 2018. The sample size is 1020 people, aged 18 - 81 years. The unified questionnaire in relation to smoking behavior and anamnesis was used by trained interviewers. To study the dynamics of smoking behavior among the population current smoking patterns and attitudes were compared with the result of previous similar surveys conducted before 2013.

Results: Overall, the percentage of current smokers in the entire sample was $37.9 \%$, former smokers who quitted smoking more than a year ago - $25.5 \%$ and never smoking - 36.6\%. The smoking prevalence among the men decreased from $61.2 \%$ (1996-1997) to $54.2 \%$ (2017-2018), $\mathrm{p}<0.001$, and among women increased from $16.1 \%$ (1996-1997) to $27.3 \%$ (2017 - 2018), $\mathrm{p}<0.0001$. Among smokers of the sample surveyed in 2017-2018 the percentage of intensive smokers ( $>=20$ cigarettes a day) was $22.0 \%$ among men and $4.1 \%$ among women. In the sample of smokers surveyed in 2010-2012 the percentage of intensive smokers was significantly higher, $46 \%$ of men and $25 \%$ of women, $p<0.001$. Out of 633 nonsmoking respondents $60,5 \%$ reported having episodes of passive exposure to tobacco smoke from the environment.

Conclusion: Despite some reduction in tobacco consumption among the population, the prevalence of TS in Russia remains one of the highest in the world. The number of current smokers among Moscow population comprises more than a third of the adult population. Fight against the tobacco epidemic requires a long-term and relentless application of the entire complex of the anti-smoking measures aimed to prevent and to stop smoking and to reach more results in decreasing smoking prevalence among population.

\section{Introduction}

The tobacco epidemic causes enormous damage to the health of the population, especially in countries with the highest prevalence of tobacco smoking (TS), to which Russia belongs [1]. TS is one of the leading modified causes of the wide-spread chronic, noncommunicable diseases, which most often lead to disability and premature mortality [2]. It is estimated that TS is the cause of more than $17 \%$ of all deaths in Russia [3]. The prevalence of TS among the population, as well as the nature of smoking behavior of individuals can change significantly with time, primarily as a result of certain measures to protect the population from the spread of TS. There are effective measures to combat the tobacco epidemic, which were recommended in the WHO Framework Convention on Tobacco Control [2] and which are taken as a basis for the formation and adoption of the Federal law of the Russian Federation "On protection of public health from the effects of surrounding tobacco smoke and the consequences of tobacco consumption" [4]. The law was approved in 2013. One of the main conditions for the successful implementation of a set of measures to prevent and eliminate TC is 
the monitoring of tobacco consumption, based on regular surveys of the population with an objective assessment of the smoking status and the main indicators of smoking behavior.

\section{Material and Methods}

Population-based survey of the sample of Moscow adult population who underwent medical check-up examination in municipal out-patient clinics, was conducted in 2017 - 2018. The sample size is 1020 people, aged 18 - 81 years. Median age - 54, mean age - 51, 71+14, 27. The 23-item unified questionnaire in relation to smoking behavior and anamnesis was used by trained interviewers. To study the dynamics of smoking behavior among the population current smoking patterns and attitudes were compared with the result of previous similar surveys conducted before 2013. The statistical analysis system was used.

\section{Results}

Overall, the percentage of current smokers in the entire sample was $37.9 \%$, former smokers who quitted smoking more than a year ago - $25.5 \%$ and never smoking - 36.6\%. The percentage of current smokers was $54 \%$ among men and $27.3 \%$ among women ( $p$ < 0.001). Historical comparison of this data on the prevalence of TS with the results of a similar survey concerning the smoking status of more than 4,000 residents of Moscow aged 20-80 years in 1996-1997, shows that the smoking prevalence among the men decreased from $61.2 \%$ (1996-1997) to 54.2\% (2017-2018), $\mathrm{p}<0.001$, and the prevalence of TS among women increased from $16.1 \%$ (1996-1997) to $27.3 \%$ (2017 - 2018), p<0.0001. In the present study women smoking prevalence rate was the highest in young age group $18-30$ years - 45,2\% and almost three times lower in the older age group $>=50$ years $-17,0 \%(p<0,05 \%)$. For men the highest smoking rate was in middle age group $30-49$ years $-65,7 \%$.

The smokers were considered to be intensive smokers if they smoked more than 20 cigarettes a day. Among smokers of the sample surveyed in 2017-2018 (387 persons) the percentage of intensive smokers was $22.0 \%$ among men and $4.1 \%$ among women. In the sample of smokers, comparable in age and place of residence, surveyed in 2010-2012 (507 persons), the percentage of people smoking more than 20 cigarettes a day, was significantly higher, $46 \%$ of men and $25 \%$ of women, $p<0.001$.

A significant majority of the current smokers $-74.8 \%$ of men and $81.1 \%$ of women reported having at least one quit attempt in the past. These attempts were without any result for majority of smokers but some of them achieved definite results. Historical comparison of samples of smokers surveyed in different years showed an increase in the percentage of people with effective attempts to stop smoking for a week and more in samples of smokers surveyed in later years. So, in the sample of smokers surveyed in 1998 -2000, 2010-2012 and 2017-2018 years among the smokers who tried in the past to quit respectively $24.8 \%, 48.9 \%$ and $60.4 \%$ persons could stop smoking for a week or more $(p<0,01)$.
In the present study of the 633 nonsmoking respondents $60,5 \%$ reported having episodes of passive exposure to tobacco smoke from the environment with a total duration of all episodes of exposure to tobacco smoke during a week of 30 minutes or more. According to Global surveys of the Russian population in 2009 and $2016[5,6]$, secondhand smoking significantly decreased at home (34.7\% in 2009 and $23.1 \%$ in 2016), in working places $(34.9 \%$ in 2009 and $21.9 \%$ in 2016), in various public places (17.0\% in 2009 and $3.6 \%$ in 2016). Out of current smokers in the last our survey $3.8 \%$ men and $0.6 \%$ woman smoked hookah. 11 persons reported using of e-cigarette, all of them from the younger age group up to 30 years (77 persons). It was found in other survey that the prevalence of hookah smoking in Russia has increased significantly during the last $10-15$ years and currently about $2.8 \%$ of the adult population ( $4.1 \%$ of men and $1.7 \%$ of women) smoke hookah [6].

\section{Conclusion}

The study results confirm a marked decline of TS prevalence, especially among men in recent years in Moscow population. Also, the percent of heavy smokers ( $>=20$ cigarettes daily) significantly decreased among current smokers. The increase in the effectiveness of attempts to quit TS was also established, which is probably due to the organization in the health service of qualified assistance in smoking cessation. All these positive changes are primarily associated with the implementation since 2013 of a complex of measures indicated in the Russian antismoking law [4]. Despite some reduction in tobacco consumption among the population, the prevalence of TS in Russia remains one of the highest in the world. In the present study the number of current smokers among Moscow population comprises more than a third of the adult population. Fight against the tobacco epidemic requires a long-term and relentless application of the entire complex of educational, administrative, medical and economic measures aimed to prevent and to stop smoking and to reach more results in decreasing smoking prevalence among population.

\section{References}

1. (2017) WHO report on the global tobacco epidemic. Monitoring tobacco use and prevention policies. WHO, Geneva.

2. (2003) WHO Framework Convention on Tobacco Control. World Health Organization, Geneva, Switzerland.

3. Marquez P, Suhrcke M, McKee M, Rocco L (2007) Adult health in the Russian Federation. Health Affairs 26(4): 1040-1051.

4. (2013) The federal law "About protection of public health from influence surrounding tobacco smoke and consequences of consumption of tobacco" of 23.02.2013 No. 15-FZ. Russia.

5. (2009) Global Adult Tobacco Survey (GATS). Russian Federation 2009. Survey was conducted by Federal State Statistics Service (Rosstat).

6. (2016) Global poll of adult population about consumption of tobacco (GATS). The Russian Federation - 2016. Survey was conducted by Federal State Statistics Service (Rosstat). 


\section{ISSN: 2574-1241}

DOI: 10.26717/BJSTR.2019.19.003343

VF Levshin. Biomed J Sci \& Tech Res

(C) $(7)$ This work is licensed under Creative

Submission Link: https://biomedres.us/submit-manuscript.php

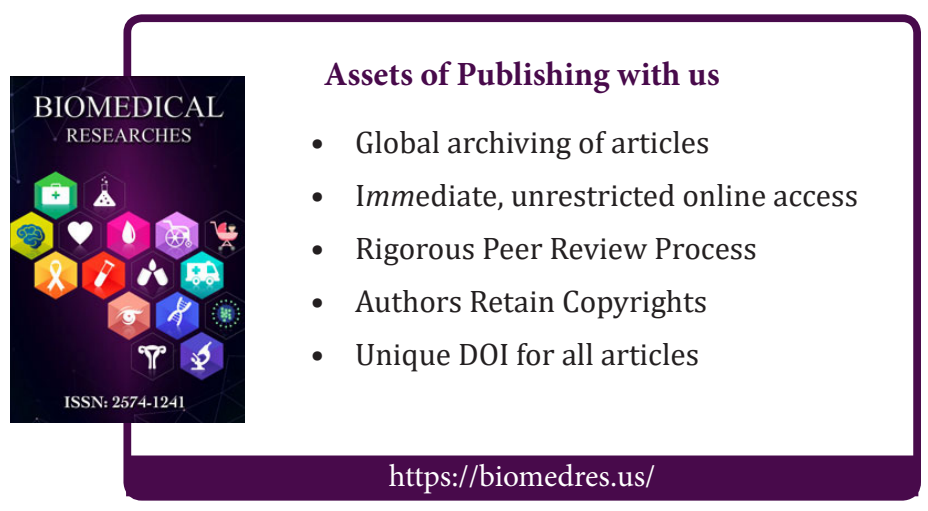

